\title{
COMPARAÇÃO ENTRE MATAS DE GALERIA NO DISTRITO FEDERAL E A EFETIVIDADE DO CÓDIGO FLORESTAL NA PROTEÇÃO DE SUA DIVERSIDADE ARBÓREA
}

\author{
Manoel Cláudio da Silva Júnior ${ }^{1}$
}

Recebido em 25/9/2000. Aceito em 20/10/2000

\begin{abstract}
RESUMO - (Comparação entre matas de galeria no Distrito Federal e a efetividade do código florestal na proteção de sua diversidade arbórea.) Este estudo foi conduzido para avaliar padrões de distribuição espacial de árvores em três matas de galeria (Pitoco, Monjolo e Taquara), na Reserva Ecológica do IBGE, no Distrito Federal. As três matas de galeria são representantes de comunidades vegetais extremamente importantes e ameaçadas, que são relacionadas com a manutenção da "saúde" do ambiente e com a oferta e qualidade de água na região. As espécies arbóreas (DAP $\geq 5 \mathrm{~cm}$ ) foram amostradas nas três matas usando-se o método de quadrantes, desde as margens dos córregos até as bordas com o cerrado, com um total de 250 pontos de amostragem em cada mata de galeria. A análise de classificação pelo TWINSPAN evidenciou comunidades florísticas peculiares de cada sítio, denominadas como "úmida", "intermediária" e "seca". As relações florísticas e estruturais entre as matas de galeria e suas comunidades foram investigadas pela análise de agrupamento (UPGMA), que reforçou o modelo da forte associação entre as comunidades e o regime de umidade nos solos. Há uma relação florística e estrutural mais forte entre comunidades de diferentes matas, sob regime similar de umidade nos solos, do que entre as comunidades úmida e seca em uma mesma mata. A análise sugere que a legislação brasileira (LEI 7.511 de 7/7/1986) não é efetiva para a proteção da diversidade arbórea das matas de galeria.
\end{abstract}

Palavras-chave - distribuição espacial de árvores, legislação brasileira, relação árvores-ambiente

\begin{abstract}
Comparison among gallery forests in the Federal District (Brazil) and the effectiveness of the brazilian legislation on protecting its tree diversity).This study was carried out to discover patterns in tree spatial distribution in three gallery forests (Pitoco, Monjolo and Taquara), within the IBGE Ecological Reserve, in the Federal District, in Central Brazil. The three gallery forests are representative of the endangered vegetation formation, which is closely related to the maintenance of the volume and quality of the water supply in the region. Tree species $(\mathrm{DBH} \geq 5 \mathrm{~cm})$ were recorded using the Point Centred-Quarter (PCQ) method, from the stream margins to the forestcerrado border, totalling 250 sampling points in each gallery forest. Classification by TWINSPAN highlighted floristic communities peculiar of each site, referred to as "moist", "intermediate" and "dry". The floristic links between the galleries and their communities were investigated by cluster analysis (UPGMA), which reinforced the model of a strong association between communities and soil moisture regime. In fact there was a stronger relationship between communities from areas of similar soil moisture, at different stream locations, than between "wet" and "dry" communities within the same stream. The analysis suggests that the Brazilian legislation (Law 7.511 of 7/7/ 1986) does not effectivelly protects the whole gallery forests woody diversity.
\end{abstract}

Key words - trees spatial patterns, Brazilian legislation, environment-trees relationships

1 Departamento de Engenharia Florestal, Universidade de Brasília, C. Postal 04357, CEP 70919-970, Brasília, DF, Brasil, e-mail: mcsj@unb.br, MMA - FNMA, CNPq-PELD. 


\section{Introdução}

Comunidades com composição florística, densidade e área basal distintas foram descritas para as matas de galeria dos córregos Monjolo, Pitoco e Taquara, as quais pertencem à mesma microbacia na Reserva Ecológica do IBGE no Distrito Federal. A distância das margens dos córregos, a inclinação do terreno e a importância fitossociológica de espécies indicadoras evidenciaram a estreita relação dessas comunidades com a topografia, gradiente de umidade e fertilidade dos solos.(Silva Júnior 1995; 1997; 1998; 1999; Silva Júnior et al. 1996).

Aqui, uma comparação qualitativa e quantitativa é conduzida utilizando-se uma análise de agrupamento divisiva (TWINSPAN) e uma aglomerativa (UPGMA), que se complementam para a avaliação das relações florísticas entre as matas e suas comunidades de árvores. Essa comparação baseia-se na idéia de que a similaridade florística entre duas áreas deveria expressar a sua afinidade ecológica (Jongman et al. 1987). Nesse contexto, pergunta-se: seriam similares as comunidades de árvores que se estabelecem desde as margens dos córregos até a borda com o cerrado?

Essa comparação florística e estrutural foi tomada como critério para a avaliação da efetividade da legislação vigente (LEI $7511 \mathrm{de}$ 7/7/1986) na proteção de toda a heterogeneidade ambiental presente nas matas de galeria do Brasil Central.

\section{Material e métodos}

A Reserva Ecológica do IBGE, situa-se nas coordenadas $15^{\circ} 56^{\prime} \mathrm{S}$ e $47^{\circ} 56^{\prime} \mathrm{W}$, com área de 1.360ha. Lá ocorrem cinco córregos denominados Taquara, Roncador, Escondido, Pitoco e Monjolo, que sustentam 104ha de matas de galeria. Os três últimos são tributários do córrego Roncador, que desemboca no Taquara, que, por sua vez, corre para fora da Reserva até alcançar o córrego do Gama, um dos formadores do Lago Paranoá. As matas que acompanham os córregos
Monjolo, Pitoco e Taquara foram utilizadas no presente estudo.

A mata do Pitoco ocorre na porção nordeste da reserva, sobre Latossolo Vermelho-escuro na maioria de sua área. A mata é mais larga na cabeceira $(160 \mathrm{~m})$, onde o córrego forma uma cascata, tornando-se mais estreita $(120 \mathrm{~m})$, com manchas espalhadas de solos encharcados mais abaixo. A topografia é moderadamente inclinada.

A mata do Monjolo localiza-se ao lado da mata do Pitoco. Ambos correm na direção sul, encontrando-se antes de se juntarem ao córrego do Roncador. A mata possui 120-160m de largura ao longo de sua extensão. O leito do córrego é bem definido, não apresentando áreas encharcadas. O solo predominante é o Latossolo Vermelho-escuro, com algumas manchas de Latossolo Vermelho-amarelo com afloramentos de plintita. A topografia é plana na cabeceira e tende a ficar mais inclinada a jusante.

A mata do Taquara está localizada na porção sudeste da Reserva. Sua cabeceira é caracterizada pela presença de barrancos que formam um leito com cerca de $3 \mathrm{~m}$ de profundidade. A jusante, a área torna-se mais plana e o leito torna-se bastante raso até perder seu caminho, com a água espalhando-se na superfície do terreno. Ali domina a Taquara (Olyra taquara Swaller), que divide a área com alguns indivíduos de samambaias arbóreas (Cyathea sp.) e poucos indivíduos de árvores de outras espécies. A área amostrada ocorre sobre Latossolo, com manchas ricas em cálcio e com afloramentos de plintita. Grande parte desta área está em terras planas a suavemente onduladas (Pereira et al. 1989; 1993; Silva Júnior 1995).

O método de quadrantes (Cottam \& Curtis 1956) foi usado para a amostragem das árvores com DAP $\geq 5 \mathrm{~cm}$. Foi locado em cada mata um total de 250 pontos de amostragem, dispostos em grades de cerca de aproximadamente 50 pontos cada, distribuídas ao longo de toda a extensão da mata, com espaçamento entre pontos e entre linhas de $10 \mathrm{~m}$, desde as margens dos córregos até os limi- 
tes das matas com o cerrado.

Os pontos de amostragem, em cada mata, Monjolo (M), Pitoco (P) e Taquara (T) foram agrupados de acordo com as distâncias das margens dos córregos. Os dados de presença e ausência das espécies por grupos de pontos, em cada mata, foram classificados usando-se o programa TWINSPAN (Hill 1979). Essa análise forneceu a distinção de grupos intermediários da vegetação, não obviamente visíveis no campo. Os grupos gerados, denominados comunidades úmida (u), intermediária (i) e seca (s) tiveram sua composição florística, densidade e área basal das espécies por hectare estimadas através de uma segunda rodada da análise fitossociológica (Silva Júnior 1995).

Uma comparação florística (qualitativa) foi conduzida com base na presença e ausência de espécies nas matas de galeria e nas suas respectivas comunidades. O índice de similaridade de Sørensen (Sørensen 1948) foi usado como medida da similaridade. O mesmo procedimento foi usado para combinar a informação florística com aquelas das densidades e áreas basais das espécies na comparação. Desta vez, o índice de Morisita (Horn 1966) foi usado como medida de similaridade. Como regra geral para ambos os índices, Sørensen e Morisita, similaridades maiores que 0,5 são consideradas altas.

A análise foi conduzida usando o método de classificação hierárquico e aglomerativo UPGMA (Kent \& Cocker 1999), que agrupa progressivamente as amostras mais assemelhadas de acordo com a medida de similaridade, até que se forme um único grupo. Os resultados são dendrogramas onde a estrutura hierárquica é expressa. A avaliação das relações ecológicas entre grupos pode ser feita em cada nível de dicotomia desde que seja possível uma interpretação biológica (James \& McCulloch 1990; Kent \& Coker 1999).

A amostragem por pontos quadrantes espaçados em $10 \mathrm{~m}$ permitiu a avaliação da efetividade da legislação vigente (Lei 7511 de
7/7/1986) parcialmente reproduzida abaixo (Fonte: site www.Senado.gov.br, legislação brasileira), através da elaboração de uma lista de espécies que geralmente são encontradas nos ambientes mais secos das matas de galeria, além dos $30 \mathrm{~m}$ protegidos por Lei, e por isso freqüentemente em risco de abate.

\section{LEI No 7.511, DE 7 DE JULHO DE 1986}

Altera dispositivos da Lei ${ }^{\circ} 4.771$, de 15 de setembro de 1965, que institui o novo Código Florestal.

O PRESIDENTE DA REPÚBLICA , faço saber que o Congresso Nacional decreta e eu sanciono a seguinte lei:

Art $1^{\circ}$ Os números da alínea a do artigo $2^{\circ}$ da Lei $n^{\circ}$ 4.771, de 15 de setembro de 1965 , que institui o novo Código Florestal, passam a vigorar com as seguintes alterações e acréscimos:

"Art. $2^{\circ}$

a)

1. de 30 (trinta) metros para os rios de menos de 10 (dez) metros de largura;

2. de 50 (cinqüenta) metros para os cursos d'água que tenham de 10 (dez) a 50 (cinqüenta) metros de largura;

3. de 100 (cem) metros para os cursos d'água que meçam entre 50 (cinquienta) e 100 (cem) metros de largura;

4. de 150 (cento e cinqüenta) metros para os cursos d'água que possuam entre 100 (cem) e 200 (duzentos) metros de largura;

igual à distância entre as margens para os cursos d'água com largura superior a 200 (duzentos) metros;

\section{Resultados e discussão}

A classificação pelo TWINSPAN indicou três comunidades florísticas, aqui designadas "seca", "intermediária" e "úmida" para as matas do Monjolo e Pitoco. Nestes casos, as comunidades "intermediárias" são uma subdivisão da comunidade úmida na Mata do Monjolo e uma subdivisão da comunidade seca na Mata do Pitoco. Duas comunidades ("seca" e "úmida") foram verificadas para a mata do Taquara. Em todos os casos, essas comunidades estão estreitamente relacionadas com a inclinação do terreno, disponibilidade de água e características físico-químicas dos solos (Silva Júnior 1995; 1997; 1998; 1999; Silva Júnior et al. 1996).

A Tab. 1 mostra os índices de Sørensen e 
Tabela 1. Matrizes de similaridade mostrando os índices de Sorensen (a) e Morisita (b-densidade e c- área basal) entre comunidades de árvores nas matas do Monjolo (M), Pitoco (P) e Taquara (T) na Reserva do IBGE.
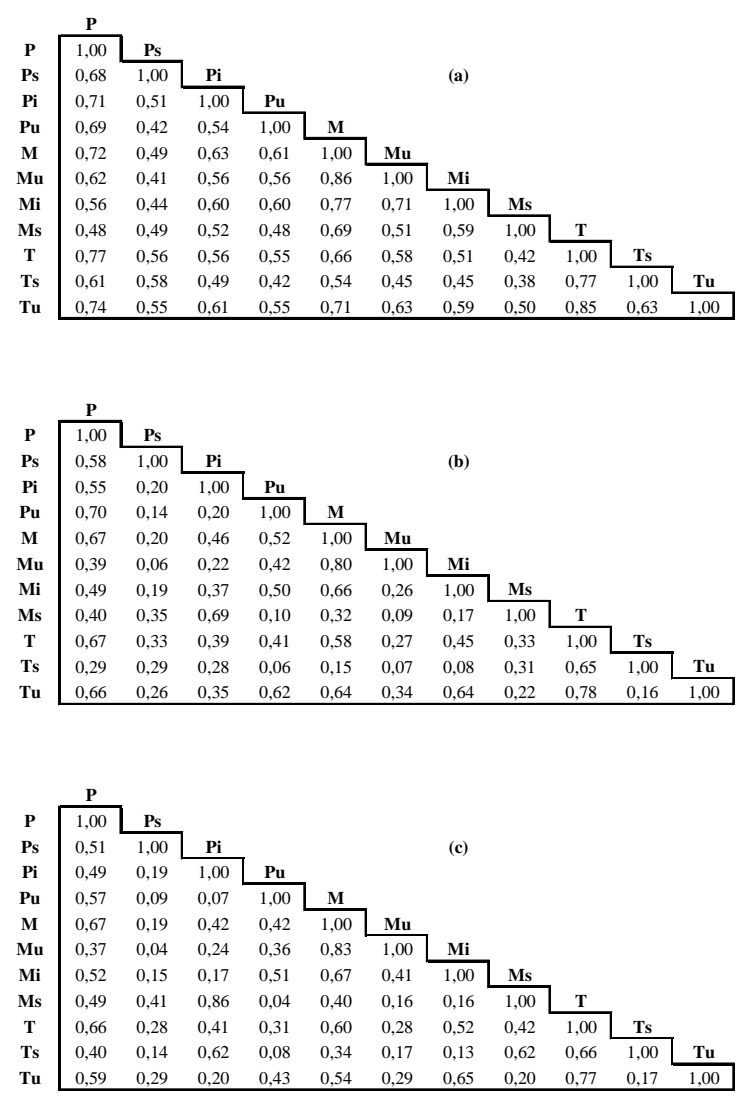

Morisita. Na Fig. 1 o dendrograma da UPGMA mostra as relações florísticas (Índice de Sørensen) entre as matas e as suas comunidades. Alguns padrões relacionados com as características físicas dos ambientes das três matas emergiram.

O Grupo A é composto pelas matas do Pitoco (P) e Taquara (T), além des suas comunidades secas Ts e Ps, pela comunidade úmida do Taquara $(\mathrm{Tu})$ e pela comunidade intermediária do Pitoco (Pi). A característica mais importante desses sítios é a presença de solos relativamente mais secos. A comunidade seca do Pitoco situa-se nos terrenos mais inclinados dentre todos. A área do Taquara amostrada situa-se em terreno plano e, em- bora o córrego se encaixe em leito profundo, bastante escavado na superfície. Essas condições topográficas resultam em solos mais bem drenados e com menor influência do lençol freático.

Dentro do grupo A, a análise enfatiza a individualidade florística de cada sítio pelos níveis de similaridade de Sørensen, que variaram entre 58 e $85 \%$.

O Grupo B foi separado do grupo A ao nível de $54 \%$ de similaridade, valor mínimo encontrado nessa análise (Fig. 1). O Grupo B inclui as comunidades úmidas do Monjolo e Pitoco. A maior umidade relativa dos solos nessas comunidades é o fator comum que relaciona os sítios. Na mata do Monjolo estão as áreas de

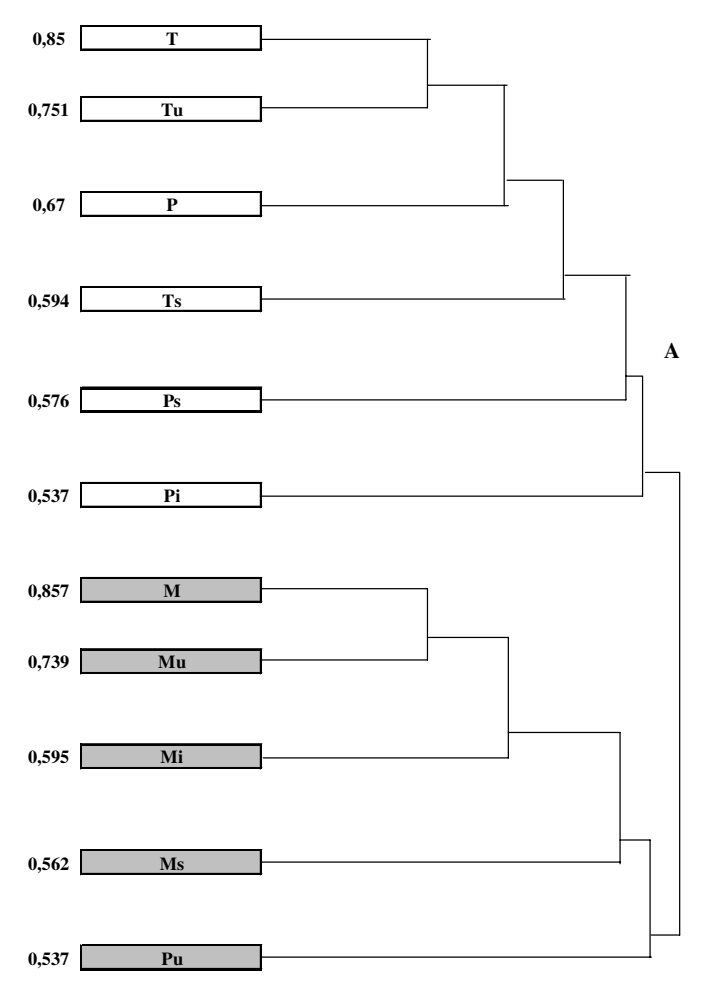

Figura 1. Classificação hierárquica (UPGMA) das comunidades de árvores intermediária (i), úmida (u) e seca (s) nas matas do Monjolo (M), Pitoco (P) e Taquara (T), usando o índice de Sorensen (presença/ausência das espécies). (A anáslise não indicou a comunidade intermediária Ti para a mata do Taquara.) 
mais forte influência dos altos níveis do lençol freático. O terreno mais plano, a presença da comunidade úmida que dista em até $80 \mathrm{~m}$ das margens do córrego e a presença no sub-bosque de densas populações de Olyra latifolia L. indicam essa situação.

A primeira dicotomia no grupo B separa a comunidade úmida do Pitoco do grupo da mata do Monjolo. Na próxima dicotomia, as comunidades úmidas do Monjolo são separadas da sua comunidade seca, indicando uma vez mais a umidade nos solos como o mais importante fator associado com a diferenciação florística entre as comunidades.

A interpretação geral é que a umidade dos solos, distinta nos diferentes ambientes ao longo do gradiente topográfico, desde as margens dos córregos até as bordas com o cerrado, é a característica ambiental mais importante que explica os níveis de agrupamento mais altos na classificação. Entretanto, os níveis de agrupamento seguintes sugerem que outras variáveis ambientais devem também estar envolvidas. Essas variáveis foram avaliadas em Silva Júnior (1995; 1997; 1998) e Silva Júnior et al. (1996).

Quando se incluem os dados de densidade das espécies na análise (Fig. 2), faz-se necessário considerar os fatores ambientais que influenciam o número de indivíduos em cada sítio. Como salientado por Harper (1990) e Bailie et al. (1987), esses fatores são principalmente resultantes da concatenação de uma série de eventos que vão desde a presença de plantas parentais férteis em floração, ocorrência da polinização, maturação dos frutos e dispersão das sementes, germinação, sobrevivência e crescimento das plântulas e, finalmente, de uma oportunidade criada pela ocorrência de um clareira no dossel, dando chance ao recrutamento aos indivíduos juvenis. Esses eventos oportunísticos são guiados, até certo ponto, pelas condições locais, que exercem considerável efeito na competição interespecífica e que determinam as associações de espécies, muitas das quais exibem preferências ambientais marcantes (Ashton 1976). Os

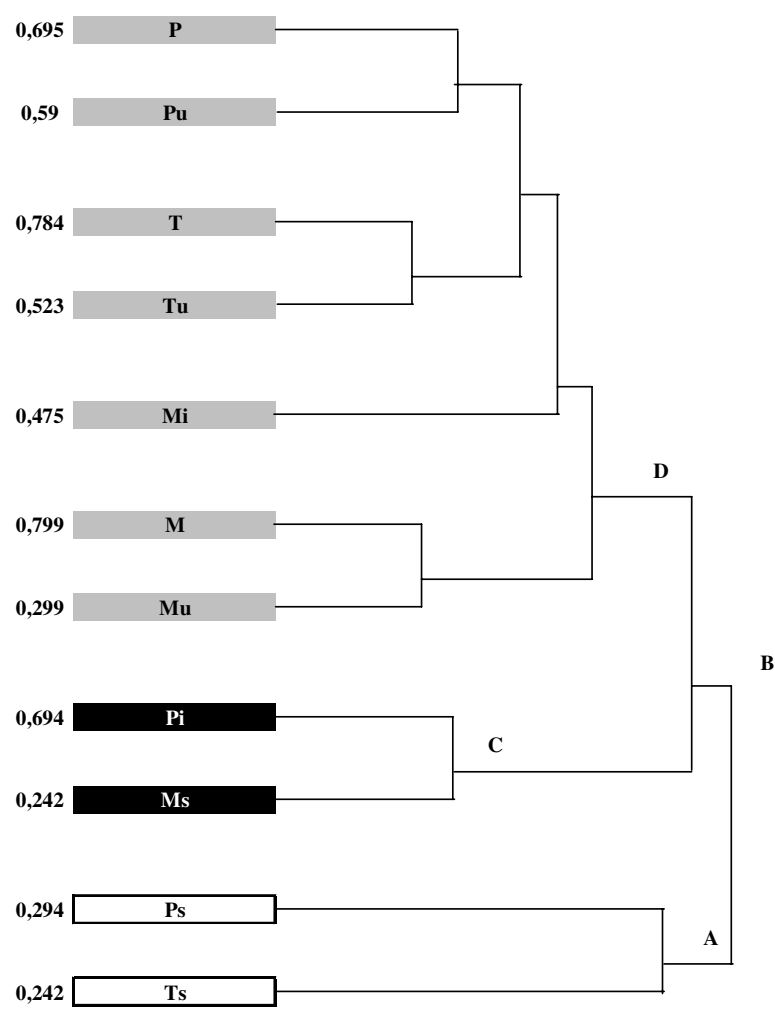

Figura 2. Classificação hierárquica (UPGMA) das comunidades de árvores intermediária (i), úmida (u) e seca (s) nas matas do Monjolo (M), Pitoco (P) e Taquara (T), usando o índice de Morisita (densidade das espécies). (A anáslise não indicou a comunidade intermediária Ti para a mata do Taquara.)

níveis de similaridade de Morisita são então interpretados como bons indicadores das similaridades ecológicas entre áreas que oferecem oportunidades semelhantes para a colonização e manutenção de um grupo das mesmas espécies.

Os índices de Morisita (densidade) e o dendrograma da UPGMA na Fig. 2 evidenciam dois grupos, $\mathrm{A}$ e $\mathrm{B}$, nos níveis mais baixos de agrupamento. O Grupo A inclui as comunidades secas do Pitoco e Taquara. Ambas ocorrem nos solos mais bem drenados, sendo Pitoco devido a topografia e Taquara como resultado do leito do córrego encaixado em leito profundo. Esses são incluídos entre os sítios mais secos no estudo.

Em um segundo nível de agrupamento, o 
grupo B é formado por um grande número de subgrupos. Neste, o grupo $\mathrm{C}$ inclui a comunidade intermediária que situa-se entre as comunidades úmida e seca no Pitoco, e a comunidade seca no Monjolo, que ocorre na área de maior inclinação dentre todas. Ambas as comunidades nesse grupo aparentemente colonizam sítios em condições mais úmidas que aquelas comunidades incluídas no grupo A. O grupo D contém todas as comunidades úmidas (Fig. 2) indicando a influência dos níveis mais altos do lençol freático.

A análise que inclui a área basal resultou na Fig. 3, que mostra no nível inferior de agrupamento a comunidade seca do Pitoco (grupo A), já mencionada como ocupando a área mais seca dentre aquelas estudadas, separadas dos demais sítios (grupo B) ao nível de $23 \%$ de similaridade de Morisita. O grupo B subdivide-se no subgrupo $\mathrm{C}$, o qual inclui a comunidade intermediária do Pitoco e a comunidade seca do Monjolo e Taquara, sugerindo condições ambientais equivalentes. O subgrupo D inclui todas as comunidades úmidas mais ou menos agregadas de acordo com seus níveis de umidade nos solos (Fig. 3).

Assim, como na comparação florística e de densidade, a análise que envolveu a área basal demonstrou que a umidade nos solos foi o fator mais importante controlando as diferenças entre os locais.

\section{A efetividade da LEI 7.511 na proteção da heterogeneidade das matas de galeria.}

A comparação entre as três matas e suas comunidades na Reserva do IBGE demonstrou que o regime similar de umidade dos solos resulta em características similares de composição florística, densidade e área basal. Assim as comunidades úmidas das três matas são mais similares entre si, do que cada uma delas com as comunidades intermediária e seca do seu próprio sítio, informação que corrobora Sampaio et al. (2000).

A comunidade úmida pode chegar aos $80 \mathrm{~m}$

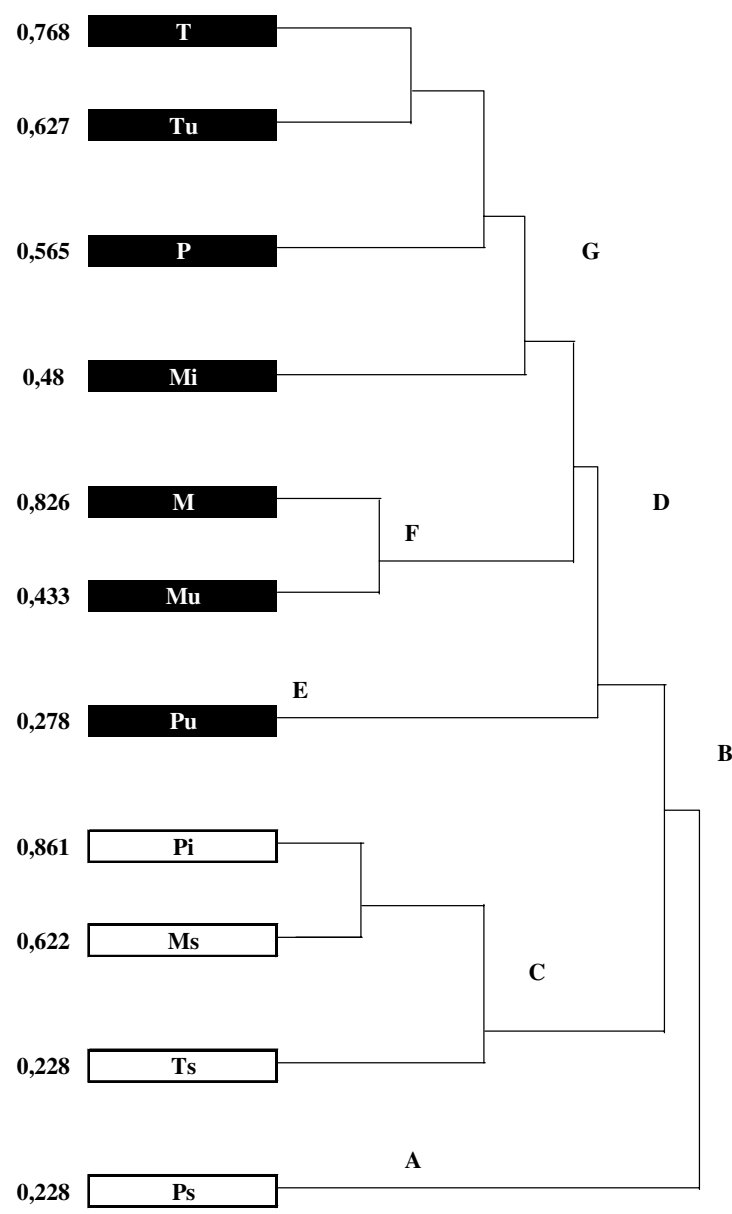

Figura 3. Classificação hierárquica (UPGMA) das comunidades de árvores intermediária (i), úmida (u) e seca (s) nas matas do Monjolo (M), Pitoco (P) e Taquara (T), usando o índice de Morisita (área basal das espécies). (A anáslise não indicou a comunidade intermediária Ti para a mata do Taquara.)

de distância das margens do córrego na caso do Monjolo, em seu trecho inicial mais plano, enquanto que a comunidade seca ocorre às margens do córrego Taquara, devido ao seu leito profundamente encaixado. Isso indica que os 30m protegidos pela LEI 7.511, aplicáveis no caso das matas aqui consideradas, não são suficientes para a proteção de toda a complexidade florística e estrutural encontradas naqueles ambientes, que variam de acordo com a topografia local e sua influência na altura do lençol freático. Em algumas situações, dependendo da topogra- 
fia da área, mesmo a comunidade úmida, geralmente mais próxima às margens dos córregos, seria apenas parcialmente protegida.

Dentre as 137 espécies amostradas nas três matas aquelas exclusivas às comunidades intermediárias e secas, mais distantes das margens dos córregos e por isso com menores possibilidades de serem protegidas pelos $30 \mathrm{~m}$ previstos na legislação vigente, estão 16 espécies (11,7\%). São elas: Aegiphila sellowiana, Alibertia edulis, Aspidosperma discolor, Cardiopetalum calophyllum, Chomelia pohliana, Cordia trichotoma, Eugenia uruguaiensis, Euplassa inaequalis, Guettarda viburnoides, Lacistema hasslerianum, Mouriri glazioviana, Ocotea pomaderroides, Platypodium elegans, Sclerolobium aureum, Terminalia argentea e Tibouchina candolleana.

A Reserva do IBGE, depois de mais de 20 anos de proteção contra o fogo, passou por um incêndio de grandes proporções em 1994, onde mesmo as matas de galeria foram severamente atingidas. A avaliação da sobrevivência de árvores nas três matas indicou mortalidades de até $60 \%$ dos indivíduos das comunidades úmidas. As espécies comuns dessas comunidades, mesmo quando mantidas em respeito a lei 7.511, estarão expostas aos freqüentes incêndios que ocorrem no cerrado vizinho, causando grande mortalidade de sua vegetação.

A rede hidrográfica no Brasil Central é caracterizada principalmente por córregos estreitos, ao longo dos quais, em função da topografia, ocorrem variações significativas no lençol, que determinam comunidades florísticas distintas como as aqui exemplificadas. Desta forma, a lei 7.511 que prevê a proteção de faixas de até $30 \mathrm{~m}$ para os córregos pequenos não é efetiva para a proteção de toda a diversidade ambiente ali encontrada. $\mathrm{O}$ papel primordial da manutenção da biodiversidade e do volume e qualidade da água necessários para o bem estar social de uma re- gião de população em crescimento acelerado, pode estar comprometido. Assim, a proteção integral dessas matas seria uma atitude estratégica e positiva da sociedade brasileira, mostrando-se comprometida para com a conservação e melhoria da qualidade de vida em nosso país.

\section{Referências bibliográficas}

Ashton, P. S. 1976. Mixed dipterocarp forest and its variation with habitat in the Malayan lowlands: a re-evaluation of Pasoh. Malayan Forester 39: 5672.

Baillie, I. C.; Ashton, P. S.; Court, M. N.; Anderson, J. A. R.; Fitzpatrick, E. A. \& Tinsley, J. 1987. Site characteristics and the distribution of tree species in Mixed Dipterocarp Forest on tertiary sediments in central Sarawak, Malaysia. Journal of Tropical Ecology 3: 201-220.

Cottam, G. \& Curtis, J. T. 1956. The use of distance measurements in phytosociological sampling. Ecology 37: 451-460.

Harper, J. L. 1990. Population biology of plants. Academic Press. London.

Hill, M. O. 1979. TWINSPAN- a FORTRAN program for arranging multivariate data in an ordered two-way table by classification of the individuals and attributes. Cornell University. Ithaca, New York.

Horn, H. S. 1966. Measurement of "overlap" in comparative ecological studies. The American Naturalist 100(914): 419-424.

James, F. C. \& McCulloch, C. E. 1990. Multivariate analysis in ecology and systematics: Panacea or Pandora's box. Annu. Rev. Ecol. Syst. 21: 129-166.

Jongman, R. H. G.; Ter Braak, C. J. F. \& Van Tongeren, O. F. R. 1987. Data analysis in community and landscape ecology. Pudoc. Wageningen.

Kent, M. \& Coker, P. 1994. Vegetation description and analysis - a practical approach. John Willey $\&$ Sons.

Pereira, B. A. S.; Furtado, P. P.; Mendonça, R. C. \& Rocha, G. I. 1989. Reserva Ecológica do IBGE (Brasília, DF): aspectos históricos e fisiográficos. B. FBCN 24: $30-43$.

Pereira, B.A. S.; Silva, M. A. \& Mendonça, R. C. 1993. Reserva Ecológica do IBGE (Brasília, DF): lista das plantas vasculares. IBGE, Brasília, DF.

Sampaio, A. B.; Walter, B. M. T. \& Felfili, J. M. 2000. Diversidade e distribuição de espécies arbóreas em duas Matas de Galeria na micro-bacia do Riacho Fundo, Distrito Federal. Acta Botanica Brasilica 
14(2): 197-214.

Silva Júnior, M. C. 1995. Tree communities of the Gallery Forests of the IBGE Ecological Reserve, Federal District Brazil. Ph.D. thesis. University of Edinburgh. Edinburgh.

Silva Júnior, M. C. 1997. Relationships between the tree communities of the Pitoco, Monjolo and Taquara Gallery Forests and Environmental Factors. Pp. 287-298. In: J. Imaña-Encinas \& C. Kleinn (Eds.) Proceedings of the International Symposium on Assessment and Monitoring of Forests in Tropical Dry Regions with special reference to Gallery Forests.

Silva Júnior, M. C. 1998. Comunidades de Árvores e sua relação com os solos na Mata do Pitoco, Reserva Ecológica do IBGE, Brasília, DF. Revta. Árvore 22: $29-40$.
Silva Júnior, M. C. 1999. Composição florística, fitossociologia e estrutura diamétrica na mata de galeria do Monjolo, na Reserva Ecológica do IBGE, DF. Boletim do Herbário Ezechias Paulo Heringer 4: 30-45.

Silva Júnior, M. C.; Furley, P. A. \& Ratter, J. A. 1996. Variations in tree communities and soils with slope in Gallery Forest, Federal District, Brazil. Pp. 451-469, vol I, Chapter 20. In: M. G. Anderson \& S. M. Brooks (Eds.) Advances in Hill Slope Processes. John Wiley \& Sons. Ltda.

Sørensen, T. A. 1948. A method of establishing groups of equal amplitude in plant sociology based on similarity of species content, and its application to analyses of the vegetation on Danish commons. K. Danske Vidensk. Selsk. Biol. Skr. 5: 1-34. 